\title{
BMJ Open Father's role in supporting breastfeeding of preterm infants in the neonatal intensive care unit: a qualitative study
}

\author{
H Denoual, ${ }^{1}$ M Dargentas, ${ }^{2,3}$ S Roudaut, ${ }^{1}$ R Balez, ${ }^{2}$ J Sizun ${ }^{1,4}$
}

To cite: Denoual H, Dargentas M, Roudaut S, et al. Father's role in supporting breastfeeding of preterm infants

in the neonatal intensive care unit: a qualitative study. BMJ Open 2016;6:e010470. doi:10.1136/bmjopen-2015010470

- Prepublication history and additional material is available. To view please visit the journal (http://dx.doi.org/ 10.1136/bmjopen-2015010470).

Received 5 November 2015 Accepted 16 February 2016

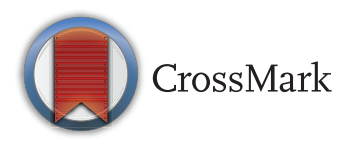

For numbered affiliations see end of article.

Correspondence to Professor J Sizun; jacques.sizun@chu-brest.fr

\section{ABSTRACT}

Objective: To analyse the social beliefs, representations and experiences of fathers of preterm newborns (NBs) regarding breastfeeding.

Design: A qualitative interview study with analysis of transcripts using the Alceste software.

Setting: A tertiary university hospital neonatal intensive care unit (NICU) in France.

Participants: 20 fathers of preterm NBs hospitalised in an NICU.

Results: The software classified $72 \%$ of the corpus into six lexical classes. Two main networks of classes emerged from the analysis: one for lactation, consisted of 'breastfeeding' and 'expression of milk' classes, and one for 'care'. The analysis demonstrated that fathers were sensitive to arguments related to the health benefits of human milk. Fathers mentioned that breastfeeding preterm NBs was constraining and tiring for their partners (multiple daily sessions of milk expression with breast pumps, time constraints and need for supplements to tube-feeding...). They also mentioned how they could genuinely help their partners during breastfeeding.

Conclusions: The results of this qualitative study provide insight into how fathers can be supportive of breastfeeding when experiencing a preterm birth. Targeted information and practical advice provided by caregivers on the first days of life can help fathers to get involved in the breastfeeding process.

\section{INTRODUCTION}

Human milk is the best food for newborns (NBs) and infants because it offers all the nutrients, calories and antibodies they need. ${ }^{1}{ }^{2}$ Unfortunately, breastfeeding (BF) rates are lower in France than in other European countries. ${ }^{3}$ For preterm NBs, feeding with human milk compared with formula results in a lower risk of developing necrotising enterocolitis. ${ }^{4}$ Moreover, there is an association between the quantity of human milk received during the hospitalisation in the neonatal intensive care unit
Strengths and limitations of this study

- Use of a qualitative methodology allowed us to collect and analyse more in-depth data about the complex beliefs, representations and experiences of fathers of preterm newborns (NB).

- Use of the Alceste software allowed the classification and rigorous analysis of text units according to the pattern of co-occurrences.

- A better understanding of fathers' experiences in the French neonatal intensive care unit could help to improve communication with and support from professionals.

- Comparison between all gestational age groups was not done given the challenge in conducting research in all gestational age groups of preterm NB.

- Fathers from low socioeconomic or ethnic groups were underrepresented.

(NICU) and the quality of the neurobehavioural development at 18 and 30 months $^{5} 6$ and an association between the duration of BF and development at 5 years. ${ }^{7}$ Thus, BF support in premature births is a priority in neonatal medicine and public health.

$\mathrm{BF}$ initiation is more complex in the context of prematurity and the following were suggested as barriers: NB vulnerabilities, specific and evolving nutritional needs, parental stress and anxiety, and a lack of training and interest from the medical and nursing staff. $^{8}$ From the parents' perspective, a lack of knowledge and misalignment between the NICU's routines and parents' needs can limit BF. The stressful nature of the NICU and the lack of privacy have also been reported as important barriers. ${ }^{9}$ The following strategies have positively impacted the $\mathrm{BF}$ rates in the NICU: increased contact between the mother and NB through Kangaroo Mother Care (skin to skin contact), support by peers, simultaneous expression of milk in both breasts, multidisciplinary training of 
professionals, and a 'Baby-Friendly Hospital Initiative' (BFHI) certification of the associated maternity ward. ${ }^{10}$ In a meta-synthesis, McInnes reported that, according to mothers, social support is more important than health professionals' support. ${ }^{11}$ The influence of the social network is underlined by other authors who found that the most useful and influential factor affecting BF duration seems to be the mother's partner. ${ }^{12}$ Studies have frequently demonstrated a positive relationship between gestational age (GA) at birth and the rate and duration of BF. ${ }^{13}$ Nevertheless, a previous study conducted in our university hospital demonstrated that there was a higher $\mathrm{BF}$ rate at discharge and at 3 months in the preterm population than in term NBs. ${ }^{14}$ Our hypothesis was that fathers of preterm NBs would support the BF initiation and duration more actively than fathers of full-term NBs.

For term birth, fathers generally support the choice of their partner to breastfeed. ${ }^{15}{ }^{16}$ In case of preterm births and hospitalisation in the NICU, fathers express a feeling of 'loss of control'. ${ }^{17}$ To keep control (or an 'illusion of control'), they try to participate in the nursing care. ${ }^{18}$ This participation seems to increase their confidence in their role as a father. ${ }^{17} 19$ Most of the published studies are from Anglo-Saxon or Scandinavian countries. Significant differences in family-centred practices have been described between European countries with a strong north-south gradient. ${ }^{20}$ These differences could exert a significant impact on parents' experiences in the NICU, specifically for $\mathrm{BF}^{21}$ Knowledge of the fathers' beliefs, attitudes and practices concerning $\mathrm{BF}$ of a preterm infant in Latin countries is a necessary step for developing targeted interventions in this specific cultural setting. ${ }^{22}$

Our hypothesis was that the involvement and support of fathers is essential for the initiation and continuation of BF in preterm NBs hospitalised in an NICU. We conducted a qualitative prospective single centre study among fathers of very preterm NBs during their NB's NICU stay and at home after discharge. The main objective of this study was to analyse the social beliefs, representations and experience of the fathers of preterm NBs concerning BF. We also analysed the factors encouraging and hindering the initiation and continuation of $\mathrm{BF}$.

\section{METHODS}

\section{Study population}

The study was conducted in a French University Hospital. The 24-bed NICU is open to parents $24 \mathrm{~h}$ a day and parents are supported to participate in the care of their NB according to the family-centred Newborn Individualised Developmental Care and Assessment Program (NIDCAP), implemented for more than 15 years. ${ }^{23} \mathrm{NB}$ care is individualised according to behavioural observations by specifically trained nurses. Nurses and physicians are strongly invited to participate in on-site BF support training. Fathers were eligible for this study if they spoke French and if their NB was born before 35 weeks of gestation, was 7-30 days old at inclusion, and had no recent severe medical deterioration.

According to the principles of grounded theory ${ }^{24}$ the number of interviews is reached when data saturation occurs and there is no emergence of new themes.

\section{Data collection}

Twenty semidirective face-to-face interviews, lasting 60-90 min, were conducted by a social psychologist (MD) and a research nurse (SR) not directly involved with families or care. The interview guide was developed from a review of the literature and preliminary interviews with caregivers. The interview was conducted according to an open and not directive format. ${ }^{25}$ Fathers were encouraged to speak as freely as possible about their own experience. The study's theme 'breastfeeding' was not announced initially to avoid influencing responses. The interview covered topics such as the pregnancy history, birth process, experience of care in the NICU, experience of skin-to skin sessions, evolution of their depiction of $\mathrm{BF}$ and the bonding process. Interviews were audio recorded, after the father's oral consent, and were transcribed verbatim. The medical data from the NB and the parents' medical and sociodemographic characteristics were prospectively collected from the medical files. To evaluate the fathers' involvement in the care, we calculated the visit index (ratio of the number of visits in the NICU over the number of hospitalisation days) and the skin to skin index (number of skin to skin sessions over the number of hospitalisation days).

\section{Data analysis}

French-speaking textual data were analysed using the statistical clustering procedures encoded in the Alceste software (Analyse des Lexèmes Co-occurents dans un Ensemble de Segments de Textes, or Analysis of Co-occurring Lexemes in a Set of Text Segments) (IMAGE, Toulouse, France). Translation of quotes into English was performed after data analysis for publication purposes.

The Alceste software, based on Benzecri's contribution to textual statistics, ${ }^{26}$ was created and developed by Reinert to detect and classify underlying discourse and narrative structures. ${ }^{27}$ This software has been applied in sociology, psychology and political science. It helps to identify the main speech patterns, ways of speaking and reflecting. These are viewed as 'shared meanings' that form social representations.

The Alceste software carries out a sequence of analytic steps. ${ }^{28}$ First, the software lemmatises words that are reduced to their roots or 'lexemes'. These lexemes are minimal units of language. The software creates a vocabulary dictionary. Second, the corpus is automatically divided into contextual units (CUs), which correspond to 'text segments' defined by their length (number of words). In our analysis, for example, CUs contained 14-16 'plenty' words, such as nouns and verbs, while 
linguistic markers, such as articles and pronouns, are not taken into account by the software for the definition of CUs. Then Alceste compares the CUs according to the vocabulary they contain. It classifies them into different groups ('lexical or word classes') and the criterion for classification is the co-occurrence of the lexemes composing the CUs. A hierarchical descending cluster analysis is performed to show the articulation and the links between lexical classes. For each lexical class, lexemes are classified according to their representative position with a $\chi^{2}$ test. The programme assigns a $\chi^{2}$ value for typical lexemes and anti-typical lexemes (words that are rarely or never used when typical lexemes of classes are used). The larger the $\chi^{2}$ value, the more significant a lexeme is for the statistical structure of the class. Each lexical class extracted using this method is related to a specific kind of discourse and narrative corresponding to specific ways of reasoning. The contents of these classes are interpreted by the researchers according to results and outputs given by the Alceste software (eg, list of lexemes, list of typical text segments for each class-elementary CU (ECU), cluster analysis, variables linked to classes, etc). Consequently, each class supports a specific discourse and narratives. Alceste helps to identify the main speech patterns, as well as ways of speaking and reflecting about the topics of interest. This analytic process warrants objectivity of data analysis, can shorten analysis time frames, provide more rigorous coding and interpretation, and reduce the risks of researcher bias. Nevertheless, the lexical classes are frequently difficult to understand and to interpret without the researcher's deep knowledge of the study and the corpus. In addition to textual data, some quantitative data were prospectively collected and analysed. These data concerned the characteristics of fathers and their NB. These quantitative data were analysed using Student's $\mathrm{t}$ test for continuous variables and the $\chi^{2}$ test for categorical variables.

\section{Ethics}

The study was conducted according to the ethical and legal standards for qualitative research. The Ouest VI Committee for the Protection of Persons (CPP) and French National Agency for Medicines and Health Products Safety (ANSM) approved the study design. All participants gave informed consent before taking part and provided written consent that their interview data could be included in publications.

A completed checklist of the consolidated criteria for reporting qualitative research (COREQ) and the fathers' interview guideline are presented in online supplementary tables A and B.

\section{RESULTS}

\section{Fathers' characteristics}

Between September 2014 and June 2015, 44 fathers were eligible and $20(45 \%)$ chose to participate in the study. Only one participant was the father of an NB not fed with mother's milk. The study included the fathers of $26 \mathrm{NBs}$, born at a mean term of $30 \pm 2.8$ weeks of gestation, with a mean $( \pm \mathrm{SD})$ birth weight of $1427( \pm 641.2) \mathrm{g}$. The social and demographic characteristics of the participating fathers and the distances between the hospital and their homes are presented in table 1 . There were no differences between included fathers and fathers who declined $(n=24)$ to participate according to age, occupation and number of previous children. The distance between home and the hospital was significantly longer for included fathers $(30.7 \pm 22.4 \mathrm{~km}$ vs 17.1 $\pm 18.8 \mathrm{~km} ; \mathrm{p}=0.02$ ).

\section{Fathers' interviews \\ 1-ALCESTE analysis}

A total of 306928 'shapes' were analysed, which corresponded to 813 pages. The software classified $72 \%$ of the corpus into six lexical classes. The hierarchical descending analysis revealed a dendrogram containing six classes (figure 1). Classes 1 to 5 ('health staff', 'skin to skin care', 'breastfeeding', 'expression of milk' and 'family circle') were linked together, while class 6 'delivery' was not. The group including classes $1-5$ contained two networks: the network 'lactation' (classes 3 and 4) and the network 'care' (classes 1, 2 and 5). Classes 3 and 4 contained 582 ECUs ( $12 \%$ of the classified ECUs) and 538 ECUs ( $11 \%$ of the classified ECUs), respectively. The network 'care' contained 2450 ECUs and accounted for $50 \%$ of the classified ECUs (table 2).

\begin{tabular}{|c|c|}
\hline \multicolumn{2}{|l|}{ Fathers' characteristics $(n=20)$} \\
\hline Age (years) (mean $\pm S D)$ & $33 \pm 4.8$ \\
\hline \multicolumn{2}{|l|}{ Occupation: (\%) } \\
\hline $\begin{array}{l}\text { Higher managerial, administrative and } \\
\text { professional }\end{array}$ & 10 \\
\hline Intermediate & 90 \\
\hline Unemployed & 0 \\
\hline $\begin{array}{l}\text { Distance of usual residence to hospital } \\
(\mathrm{km})(\text { mean } \pm \mathrm{SD})\end{array}$ & $31 \pm 22.4$ \\
\hline \multicolumn{2}{|l|}{ Involvement index in the care: } \\
\hline Visit index* & $1.12 \pm 0.47$ \\
\hline Skin to skin index† & $0.32 \pm 0.21$ \\
\hline 1st child (\%) & 40 \\
\hline \multicolumn{2}{|l|}{ NB characteristics $(n=26)$} \\
\hline Females (\%) & 53 \\
\hline Gestational age (weeks) (mean $\pm S D)$ & $30 \pm 2.8$ \\
\hline Birth weight $(g)($ mean $\pm S D)$ & $1427 \pm 641.2$ \\
\hline Caesarean section (\%) & 75 \\
\hline $\begin{array}{l}\text { Length of hospitalisation (days) } \\
\text { (mean } \pm \mathrm{SD})\end{array}$ & $55 \pm 31.2$ \\
\hline \multicolumn{2}{|c|}{$\begin{array}{l}\text { "Visit index (ratio of the number of visits in the NICU over the } \\
\text { number of hospitalisation days). } \\
\text { †Skin to skin index (number of skin to skin sessions over the } \\
\text { number of hospitalisation days). } \\
\text { NBs, newborns; NICU, neonatal intensive care unit. }\end{array}$} \\
\hline
\end{tabular}


Figure 1 Dendrogram of the classification of elementary contextual units (ECU): descending hierarchical classification with the percentage of the classified ECUs created by the Alceste software.
Class 1 Class 5

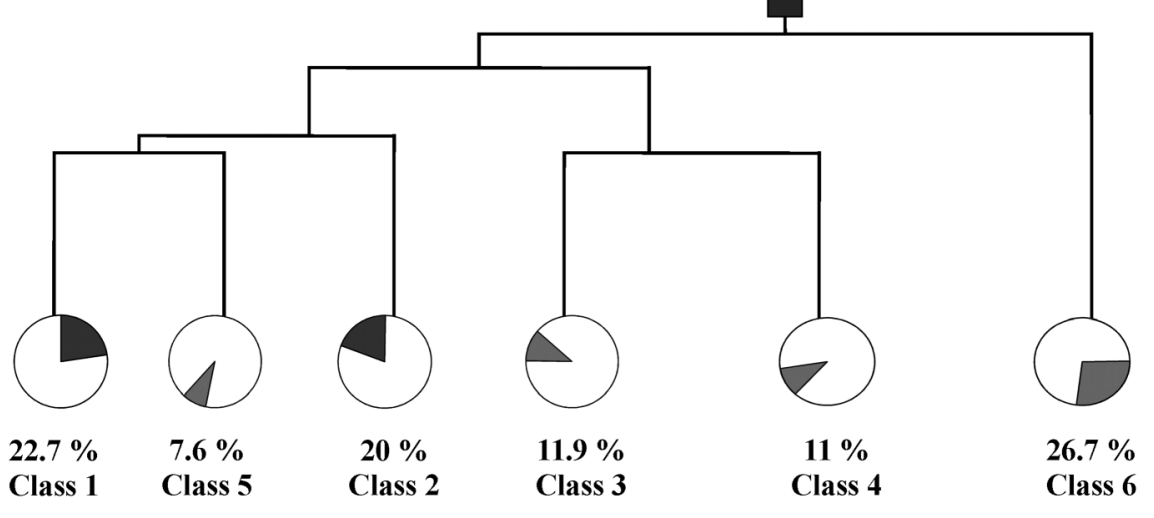

Since our objectives were to study perceptions of fathers about BF and practices to support them in the first days after birth, the analysis was focused especially on classes 3 and 4 . We did not analyse class 6, which referred to 'delivery', or network 'care' (classes 1, 2 and 5), which appeared to closely correspond with the lactation classes.

\section{2-Contents Of the lactation classes (classes 3 and 4) Class 3 related to BF}

The fathers referred to the benefits of $\mathrm{BF}$ and to the decision shared with their partner to initiate BF. Typical words were, for example: 'health', 'natural', 'choice' and 'plan'. In this form of discourse, fathers seemed to be thinking about, arguing about and reflecting on $\mathrm{BF}$ issues and beliefs. Fathers often used the pronoun 'I' and stated 'I think' to indicate during the interview that they wanted to provide their ideas, beliefs and attitudes about BF.

Issues on $\mathrm{BF}$ seem to have been discussed before birth, between parents and sometimes with a health professional, but the decision was made during the NICU stay. Some fathers referred to NICU staff as having a positive discourse on $\mathrm{BF}$ and giving thorough explanations about the benefits of human milk. This seemed to influence the maternal decision to express milk.

The BF plan was often rediscussed when the parents were informed of the feeding of their own infant with pooled donor milk in case of a lack or insufficiency of mother's milk. Donor's human milk proposal in most

Table 2 Most typical and antitypical words for each class extracted by Alceste

\begin{tabular}{|c|c|c|}
\hline $\begin{array}{l}\text { Classes ( } \% \text { of the } \\
\text { classified ECUs) }\end{array}$ & Typical words $\left(\chi^{2}\right)$ & Antitypical words \\
\hline $\begin{array}{l}\text { Class 1: 'health staff' } \\
(22.7 \%)\end{array}$ & $\begin{array}{l}\text { Nurse (181), parent (135), to care (120), unit (115), room (93), } \\
\text { social }(91) \text {, to meet }(91) \text {, help (80), to discuss (69), thing (66), } \\
\text { psychologist/psychology (65), to speak (56), team (55), } \\
\text { observation (51) }\end{array}$ & $\begin{array}{l}\text { Milk, to pump, breast, to } \\
\text { breastfeed, skin, to give birth }\end{array}$ \\
\hline $\begin{array}{l}\text { Class 2: 'skin to skin } \\
\text { care' }(20 \%)\end{array}$ & $\begin{array}{l}\text { Skin (260), fear (195), to touch (164), hand (162), diaper (146), } \\
\text { care (122), to feel (83), little ( } 76) \text {, to caress }(76) \text {, to reassure }(63) \text {, } \\
\text { relation (62), to change }(62) \text {, baby }(54) \text {, movement (57), bath (54), } \\
\text { sense (53), fragile/fragility (53) }\end{array}$ & $\begin{array}{l}\text { Milk, to breastfeed, to pump, } \\
\text { breast, week }\end{array}$ \\
\hline $\begin{array}{l}\text { Class 3: 'breastfeeding' } \\
(11.9 \%)\end{array}$ & $\begin{array}{l}\text { Milk (987), to breastfeed (972), motherly (418), to give (329), to } \\
\text { pump (182), bottle (135), breast (130), decision (117), antibody } \\
(117) \text {, choice (98), plan (88), duration (78), image (71), to disturb } \\
(68) \text {, opinion }(67) \text {, cow (65), artificial (65) }\end{array}$ & Little, care, parents, skin, unit \\
\hline $\begin{array}{l}\text { Class 4: 'expression of } \\
\text { milk' }(11 \%)\end{array}$ & $\begin{array}{l}\text { To pump (449), milk (348), night (312), to wake up (281), breast } \\
\text { (253), to suck (208), tiredness/tired (187), to sleep (178), quantity } \\
(154) \text {, hour (137), bottle (134), fridge (89), to try (84), finger (77), } \\
\text { to increase (76), to constrain (76), bed (70) }\end{array}$ & $\begin{array}{l}\text { Child, to speak, to give birth, } \\
\text { to reassure }\end{array}$ \\
\hline $\begin{array}{l}\text { Class 5: 'family circle' } \\
(7.6 \%)\end{array}$ & $\begin{array}{l}\text { Friend (431), sister (403), brother (365), family (323), grandparents } \\
(248) \text {, circle (182), close relation (158), mother (105), to come } \\
\text { (81), grand-mother (78), cousin ( } 75) \text {, school (69), announcement } \\
\text { (64), person (63), parents (59), boy (55), family (55) }\end{array}$ & $\begin{array}{l}\text { Milk, nurse, to explain, care, } \\
\text { hour }\end{array}$ \\
\hline $\begin{array}{l}\text { Class 6: 'delivery' } \\
(26.7 \%)\end{array}$ & $\begin{array}{l}\text { To give birth (272), week (200), pregnancy (172), risk (146), } \\
\text { caesarean (146), contraction (102), surgery (90), birth (89), } \\
\text { echography (74) }\end{array}$ & $\begin{array}{l}\text { Milk, to breastfeed, to pump, } \\
\text { to give, nurse, breast }\end{array}$ \\
\hline
\end{tabular}


cases encouraged those reluctant mothers to breastfeed their preterm NB. Some fathers believed donor's human milk to not be as good as mother's milk, with the implicit idea of a potential negative impact on their NB.

Participant $\mathrm{N}^{\circ} 13$ (intermediate occupation, father $>35$ years, NB between 29 and 32 GA, first child, mother's milk using a bottle)

'Well, the problem is that formula is nice, but we do not know what is inside, it is bothering, as for the donor milk'

Participant $\mathrm{N}^{\circ} 16$ (intermediate occupation, father $<35$ years, NB between 29 and 32 GA, first child, mother's milk: breast and bottle)

'Was the nutrition of the donor appropriate? How the milk has been chosen? It was something that she did not know and we still don't know.'

Participant $\mathrm{N}^{\circ} 2$ (intermediate occupation, father $<35$ years, NB between 29 and 32 GA, mother's milk and formula)

'After that, the donor milk... that was what pushed us to decide; now I can remember.'

On the basis of the general perception of the maternal milk, the medical benefits of BF seemed to be generally known by our respondents. Fathers insisted on the positive impact on the health of their NB, for instance, for infection control in preterm NBs. A preference for mother's milk versus formula was often cited.

Participant $\mathrm{N}^{\circ} 1$ (intermediate occupation, father $<35$ years, NB between 25 and 29 GA, mother's milk: breast and bottle)

'The mother's milk, we knew that it was better than formula because of antibodies and so on.'

Participant $\mathrm{N}^{\circ} 23$ (intermediate occupation, father $>35$ years, NB >32 GA, mother's milk: breast and bottle)

'Artificial, industrial. This is the main reason to give her more... how do they call that?... the human milk immunises much more an infant against external aggression.'

Fathers' knowledge about the benefits of BF seemed limited to the short term and immune aspects. There was no discourse about the long-term positive impact on neurobehavioural development, one of the major concerns for parents of preterm NBs. Another positive representation of $\mathrm{BF}$ was its 'natural' character. The process of feeding with mother's milk was viewed as 'natural' when compared with formula, more adapted to the idealisation of motherhood. These fathers also expressed their wish to pursue a generally more natural way of life for their family.
Participant $\mathrm{N}^{\circ} 11$ (intermediate occupation, father $<35$ years, NB between 29 and 32 GA, mother's milk: breast and bottle)

'For me, it's natural and very nice. I want to kiss her more because she is giving her own milk, she is feeding her daughter, I find that fantastic.'

Participant $\mathrm{N}^{\circ} 16$ (higher occupation, father $<35$ years, NB between 29 and 32 GA, first child, mother's milk: breast and bottle)

'I wanted her to breastfeed, sure that seems more natural. That was my point of view, I don't know but this is my personal view about the beginning of motherhood.'

Fathers often claimed that the final decision for $\mathrm{BF}$ should come from their partner, as it was her own body and as she needed to make efforts to breastfeed. Fathers appeared impressed by their partner's BF efforts.

Participant $\mathrm{N}^{\circ} 10$ (intermediate occupation, father $<35$ years, NB between 25 and 29 GA, mother's milk and formula)

'Because I think I wanted to give her the choice without forcing her; that's my opinion, a man's opinion, we can't force a woman to breastfeed if she does not want to'

Few negative representations of $\mathrm{BF}$ have been expressed by fathers. One was that BF will not allow them to participate in the NB's care. This concern probably had an impact on the decision to use a bottle instead of direct BF.

Participant $\mathrm{N}^{\circ} 1$ (intermediate occupation, father $<35$ years, NB between 25 and 29 GA, mother's milk: breast and bottle)

'We said that it will be good to do it, not to breastfeed, not to put him on the breast but only to express milk and to give it using a bottle so that I could participate to feed.'

Another negative representation of BF was the comparison of the mother to a 'dairy cow', even as a joke, which could negatively impact the parent's feeding choice or BF duration

Participant $\mathrm{N}^{\circ} 18$ (intermediate occupation, father $>35$ years, NB >32 GA, first child, mother's milk and formula)

'No, maybe, yes, this could have disturbed her; she finds that is like a "dairy cow", but by now, she gets used to do that, that is, and it's temporary.'

The intimacy of BF was another concern. Some fathers felt uncomfortable imagining their partner BF in public.

Participant $\mathrm{N}^{\circ} 9$ (intermediate occupation, father $<35$ years, NB >32 GA, first child, mother's milk and formula) 
'It does not work correctly, and to give the bottle in public, it's very good, isn't it? I'm not comfortable with the image of a baby breastfed in public; even if natural, it's very private.'

Another negative element was the consequence of BF on the infant-mother relationship.

Participant $\mathrm{N}^{\circ} 22$ (intermediate occupation, father $<35$ years, NB between 29 and 32 GA, formula)

MD: 'what do you think about mothers who have breastfed a long time?' FATHER: I find them, [..., I don't know, it's just an opinion, too much exclusive with their child.'

\section{Class 4 related to milk expression}

Class 4 was associated with class 3 inside the network 'breastfeeding'. This class showed forms of discourse focusing on practices: fathers spoke about the pumps and the different techniques to transfer the expressed milk to the baby. Most typical words were 'pump', 'tiredness', 'constraint' and 'amount/quantity'. These expressions were specifically associated with fathers weakly involved in the skin-to-skin care. The idea of constraint, associated with milk expression by pumps during the first weeks, was often suggested. Fathers noted that the expression sessions, at regular intervals, were exhausting for the mother, mostly during the night. This was a source of concern for fathers who worried about their partner's health, pushing them to suggest discontinuation of BF.

Participant $\mathrm{N}^{\circ} 11$ (intermediate occupation, father $<35$ years old, NB between 29 and 32 GA, mother's milk: breast and bottle)

MD: 'does she succeed in waking up during the night?' FATHER: 'when she is sleeping at home, I'll say frankly, she failed to wake up twice and I said 'stop!"

Participant $\mathrm{N}^{\circ} 14$ (intermediate occupation, father $>35$ years, NB between 29 and 32 GA, first child, mother's milk: breast and bottle)

'But I understand that it is difficult. Days are tiring and using the alarm clock at night to express the milk, it's quite difficult. So she has a quite small production.'

'Sometimes, even with the alarm clock, she is not able to wake up, she is too tired.'

One way to cope with the mother's tiredness appeared to be the decreasing of milk expression at night. Fathers said that they did not follow the number of sessions suggested by the staff, without any evident negative impact on milk production.

Participant $\mathrm{N}^{\circ} 14$ (intermediate occupation, father $>35$ years, NB between 29 and 32 GA, first child, mother's milk: breast and bottle)
'We were told that the ideal is to express milk not less than 8 times a day, and it's sure that she has some difficulties to do it. Seven is a maximum, eight very difficult. She has some troubles to use the alarm clock during the night, to express during the night.'

Some fathers explained how they could help their partner in a practical way. Once the milk was expressed, the 'cold chain' was often managed by the fathers.

Participant $\mathrm{N}^{\circ} 12$ (intermediate occupation, father $>35$ years, NB >32 GA, mother's milk, breast and formula)

'In fact, when she is pumping, I'm still sleeping and when she stops, she awakes me and I put the milk in a bottle, seal it, and stick the label and store into the fridge.'

Other fathers expressed the link between milk production and milk expression through the following details: minimal number of daily sessions, timing, and quantities of produced and stored milk. This 'mathematical' idea of milk expression was perceived as constraining yet soothing, that is, there is a strict framework with quantitative objectives that fathers seemed to have some control over. Some fathers seemed proud to make detailed reports of milk production, finding a rewarding role even if it was demanding for their partner.

Participant $\mathrm{N}^{\circ} 1$ (intermediate occupation, father $<35$ years, NB between 25 and 29 GA, mother's milk: breast and bottle)

FATHER: 'To hold him, to hug him, to weigh, to stimulate him before putting him on breast, we share this role in fact. Really the mom holds him on the breast and I'm doing everything that is needed.'

Similar quantitative goals were reported for the NB feeding (tube-feeding or finger-feeding to supplement $\mathrm{BF})$.

Participant $\mathrm{N}^{\circ} 1$ (intermediate occupation, father $<35$ years, NB between 25 and 29 GA, mother's milk: breast and bottle)

'Thus the baby is weighed before and then after the breastfeeding to know how much he has drunk and then a tube feeding is performed to complete, to give him his optimal dose to be able to grow properly.'

\section{DISCUSSION}

Our qualitative study explored the beliefs, representations and experiences of the fathers of preterm NBs about BF. This study highlighted the fathers' knowledge of short-term medical benefits of human milk compared with formula. It also showed the impact of discussions with NICU staff on the decision to breastfeed. Expression of milk was reported as a constraining and tiring experience for mothers. Fathers' wishes to actively 
support their partner and participate in practical actions were mainly focused on technical management of the expressed milk.

Few studies have analysed the role of fathers in the $\mathrm{BF}$ process and most of them concerned term NBs. ${ }^{16}{ }^{29} \mathrm{~A}$ lack of familial support, particularly from fathers, has been identified as a barrier to $\mathrm{BF}^{30}$ Fathers of term NBs are sensitive to arguments about the benefits of human milk on the health of their child, recognise the natural characteristic, and feel empathy for the efforts of their partners. $^{30} 31$ They often report being excluded from antenatal BF education or being considered unimportant in the postnatal support. ${ }^{31}$ In our study of preterm births, fathers seemed to find a role in 'the technical tasks' surrounding the expression of milk, as reported previously. ${ }^{32}$ Assisting their partner in the milk expression sessions and participating in routine domestic responsibilities were reported as supporting behaviours by Smith $e t a l .{ }^{33}$ These technical roles could be seen as a way to 'keep control' during this stressful period. ${ }^{18}$

Interviews with staff members from our NICU about $\mathrm{BF}$ appeared to have a great impact on fathers. In addition to the information content, the positive attitude of health professionals is an important factor for fathers' support. A recent European study demonstrated that French NICU staff members from the Ile de France region have been more preoccupied by the potential risks of infections associated with human milk and expressed more concerns about the difficulties of milk expression than professionals from an Italian region. ${ }^{21}$ The proportion of infants receiving human milk at discharge was significantly lower in these French NICUs $(<35 \%)$ compared with the Italian NICUs $(>55 \%)$. Our NICU team has been extensively trained in lactation support and in family-centred developmental care. These facts most likely could have an impact on our staff's BF knowledge, attitude and communication with parents. ${ }^{34}$ The gathering of information and the NICU's practices were adjusted according to the parent's needs and this seemed essential in helping parents to initiate and continue $\mathrm{BF}^{9}$

Our study had some limitations. One was that the sample included fathers of NBs with a mean GA age of 30 weeks. Extremely preterm NBs are exposed to more severe acute and chronic illnesses than moderate preterm NBs. Comparison between all GA groups was not done given the challenge in conducting research in all GA groups of preterm NB. Second, only volunteer fathers participated in the study and this may have resulted in recruiting fathers with more interest or who were more involved in the care of their NBs. The group could be non-representative of the general population as fathers from low socioeconomic or ethnic groups were underrepresented. We used the Alceste software, a specific tool for identifying redundant and consensual kinds of speech and narratives based on lexical co-occurrence. Since this software is not adapted for a content analysis on particular themes, we suggest completing the analysis using a CAQDAS software, such as NVivo. ${ }^{35}$

The results of this study provided an insight into how fathers can be supportive of $\mathrm{BF}$ while experiencing a preterm birth. In line with the literature, fathers' knowledge about the positive impact of BF on NBs' long-term outcomes could be improved through education. ${ }^{29} 30$ The ideal timing for fathers' education in case of preterm birth is unknown. Consistent with Sherriff et $a \hat{l}^{36}$ who reported on the importance of fathers' role during BF (being there, bathing, changing, skin to skin), our study showed the significance of fathers' support and encouragement for participation in human milk sampling, storage and transfer. Sherriff $e t a l^{36}$ also suggested assisting fathers in their abilities to overcome negative perceptions of $\mathrm{BF}$ from others.

\section{Author affiliations}

${ }^{1} \mathrm{CHU}$ Brest, Pôle de la Femme de la Mère et de l'Enfant, Brest, France ${ }^{2}$ Université de Bretagne occidentale, Centre de Recherches en Psychologie, Cognition et Communication (CRPCC), EA 1285, Brest, France

${ }^{3}$ Centre Edgar Morin (UMR 8177, Ecole des Hautes Etudes en Sciences Sociales), Paris, France

${ }^{4}$ Université de Bretagne occidentale, UFR Médecine et Sciences de la Santé, EA 4686 EPS, Brest, France

Acknowledgements The authors are grateful for the time and insights provided by all the study participants. The authors are also thankful for the helpful support by Zarrin Alavi, INSERM CIC 1412, CHRU Brest France and Lolita Lorgeray.

Contributors MD, RB and JS conceived and designed the study. HD, MD and SR collected the data. HD and MD analysed the data. HD, MD, RB and JS wrote the paper.

Funding This study was supported by a grant from the French Ministry of Health (PHRIP 2013 13-0502).

Competing interests None declared.

Patient consent Obtained.

Ethics approval Approval was obtained from the Ouest VI Committee for the Protection of Persons (CPP) and the French National Agency for Medicines and Health Products Safety (ANSM).

Provenance and peer review Not commissioned; externally peer reviewed.

Data sharing statement No additional data are available.

Open Access This is an Open Access article distributed in accordance with the Creative Commons Attribution Non Commercial (CC BY-NC 4.0) license, which permits others to distribute, remix, adapt, build upon this work noncommercially, and license their derivative works on different terms, provided the original work is properly cited and the use is non-commercial. See: http:// creativecommons.org/licenses/by-nc/4.0/

\section{REFERENCES}

1. Turck D. Plan d'action: allaitement maternel. Programme national Nutrition Santé. 2010. http://www.sante.gouv.fr/lMG/pdf/Rapport Plan_daction_allaitement_Pr_D_Turck.pdf

2. American Academy of Pediatrics. Policy statement: breastfeeding and the use of human milk. Pediatrics 2012;129:e827-41.

3. Bonet M, Blondel B, Agostino R, et al. Variations in breastfeeding rates for very preterm infants between regions and neonatal units in Europe: results from the MOSAIC cohort. Arch Dis Child Fetal Neonatal Ed 2011;96:F450-2.

4. Quigley MA, Henderson G, Anthony MY, et al. Formula milk versus donor breast milk for feeding preterm or low birth weight infants. Cochrane Database Syst Rev 2007;4:CD002971. 
5. Vohr BR, Poindexter BB, Dusick AM, et al. NICHD Neonatal Research Network. Beneficial effects of breast milk in the neonatal intensive care unit on the developmental outcome of extremely low birth weight infants at 18 months of age. Pediatrics 2006;118: e115-23.

6. Vohr BR, Poindexter BB, Dusick AM, et al. National Institute of Child Health and Human Development National Research network. Persistent beneficial effects of breast milk ingested in the neonatal intensive care unit on outcomes of extremely low birth weight infants at 30 months of age. Pediatrics 2007;120:e953-9.

7. Rozé JC, Darmaun D, Boquien CY, et al. The apparent breastfeeding paradox in very preterm infants: relationship between breast feeding, early weight gain and neurodevelopment based on results from two cohorts, EPIPAGE and LIFT. BMJ Open 2012;2: e000834.

8. Callen J, Pinelli J, Atkinson S, et al. Qualitative analysis of barriers to breastfeeding in very-low-birthweight infants in the hospital and postdischarge. Adv Neonatal Care 2005;5:93-103.

9. Alves E, Rodrigues C, Fraga S, et al. Parents' views on factors that help or hinder breast milk supply in neonatal care units: systematic review. Arch Dis Child Fetal Neonatal Ed 2013;98. F511-17.

10. Renfrew MJ, Craig D, Dyson L, et al. Breastfeeding promotion for infants in neonatal units: a systematic review and economic analysis Health Technol Assess 2009;13:1-146.

11. Mclnnes RJ, Chambers JA. Supporting breastfeeding mothers: qualitative synthesis. J Adv Nurs 2008;62:407-27.

12. Kaufman KJ, Hall LA. Influences of the social network on choice and duration of breast-feeding in mothers of preterm infants. Res Nurs Health 1989;12:149-59.

13. Maia C, Brandão R, Roncalli $A$, et al. Length of stay in a neonatal intensive care unit and its association with low rates of exclusive breastfeeding in very low birth weight infants. J Matern Fetal Neonatal Med 2011;24:774-7.

14. Vessière-Varigny M, Garlantézec R, Gremmo-Feger G, et al. Allaitement maternel du nouveau-né prématuré: évaluation prospective dans une maternité universitaire. Arch Pediatr 2010;17:1416-24.

15. Rempel LA, Rempel JK. The breastfeeding team: the role of involved fathers in the breastfeeding family. J Hum Lact 2011;27:115-21.

16. Avery AB, Magnus JH. Expectant fathers' and mothers' perceptions of breastfeeding and formula feeding: a focus group study in three US cities. J Hum Lact 2011;27:147-54.

17. Lindberg B, Axelsson K, Ohrling K. Adjusting to being a father to an infant born prematurely: experiences from Swedish fathers. Scand $J$ Caring Sci 2008;22:79-85.

18. Fegran L, Helseth S, Fagermoen MS. A comparison of mothers' and fathers' experiences of the attachment process in a neonatal intensive care unit. J Clin Nurs 2008;17:810-16.
19. Arockiasamy V, Holsti L, Albersheim S. Fathers' experiences in the neonatal intensive care unit: a search for control. Pediatrics 2008;121:e215-22.

20. Greisen G, Mirante N, Haumont D, et al. ESF Network. Parents, siblings and grandparents in the Neonatal Intensive Care Unit. A survey of policies in eight European countries. Acta Paediatr 2009:98:1744-50.

21. Bonet M, Forcella E, Blondel B, et al. Approaches to supporting lactation and breastfeeding for very preterm infants in the NICU: a qualitative study in three European regions. BMJ Open 2015;5:e006973.

22. Sherriff N, Hall V. Engaging and supporting fathers to promote breastfeeding: a new role for Health Visitors? Scand J Caring Sci 2011;25:467-75.

23. Als H, McAnulty GB. The Newborn Individualized Developmental Care and Assessment Program (NIDCAP) with Kangaroo Mother Care (KMC): comprehensive care for preterm infants. Curr Womens Health Rev 2011;7:288-301.

24. Creswell JW. Qualitative inquiry and research design. Choosing among five approaches. Thousand Oaks, CA: Sage Publications, 2007.

25. Rogers CR. The nondirective method as a technique for social research. Am J Sociol 1945;50:279-83.

26. Benzecri JP. L'analyse des données. Paris: Dunod, 1973.

27. Noël-Jorand MC, Reinert M, Giudecelli S, et al. Schizophrenia: the quest for a minimum sense of identity to ward off delusional disorder. Can J Psychiatry 2004;49:394-7.

28. Stoneman $P$, Sturgis $P$, Allum N. Exploring public discourses about emerging technologies through statistical clustering of open-ended survey questions. Public Underst Sci 2012;22:850-68.

29. Mitchell-Box K, Braun KL. Fathers' thoughts on breastfeeding and implications for a theory-based intervention. J Obstet Gynecol Neonatal Nurs 2012;41:E41-50.

30. Van Wagenen SA. Attitudes toward breastfeeding among an Internet panel of U.S. males aged 21-44. Matern Child Health $J$ 2015;19:2020-8.

31. Brown A, Davies R. Fathers' experiences of supporting breastfeeding: challenges for breastfeeding promotion and education. Matern Child Nutr 2014;10:510-26

32. Sweet L, Darbyshire P. Fathers and breast feeding very-low-birthweight preterm babies. Midwifery 2009;25:540-53.

33. Smith JR, Jamerson PA, Bernaix LW. Fathers' perceptions of supportive behaviours for the provision of breast milk to premature infants. Adv Neonatal Care 2006;6:341-8.

34. Hedberg Nyqvist K. Breastfeeding support in neonatal care: An example of the integration of international evidence and experience. N Infant Nurs Rev 2005;5:34-48.

35. Banner DJ, Albarrran JW. Computer-assisted qualitative data analysis software: a review. Can J Cardiovasc Nurs 2009;19:24-31.

36. Sherriff N, Panton C, Hall V. A new model of father support to promote breastfeeding. Community Pract 2014;87:20-4. 